\title{
The Functioning of Inter-modal Competition in the Transportation Market: Evidence from the Entry of Low-cost Airlines in Germany
}

\author{
GUIDO FRIEBEL * \\ Goethe University Frankfurt and Toulouse School of Economics, CEPR \\ MARKO NIFFKA \\ MTU
}

\begin{abstract}
We investigate the entry of low-cost airlines (LCAs) in the German market. The strong competitive pressure of LCAs forced incumbent air and rail operators to reconsider their pricing strategy. Lufthansa reacted by a drastic cut of all prices for all intra-German origin and destinations (O\&Ds). The physical conditions of DB, the incumbent railroad operator, made it harder to react. Being an open system, changing the price system on one O\&Ds has substantial opportunity costs on other O\&Ds in the same rail network. This imposes constraints on price strategies LCA and Lufthansa do not have to satisfy to the same extent.
\end{abstract}

\section{Introduction}

Throughout the last years, low-cost airlines (LCAs) have gained substantial market shares. This trend has initially been confined to the US and the UK, but recently, LCAs have also entered the continental European markets. While there is some research about the interaction of LCAs and incumbent network airlines, ${ }^{1}$ little is known about inter-modal competition between airlines (both LCAs and network carriers) and train operators.

However, the functioning of inter-modal competition in the passenger market is an important problem for Europe, for a number of reasons. First, trains hold a large share in the market for long-haul passenger traffic. According to internal data of the Deutsche $B a h n$, the rail market share in long distance-connections is $12 \%$. Incumbent rail operators maintain and expand high-speed trains that compete for many of the origin and destinations potentially served by LCAs. (Examples are Cologne - Paris; Paris - London; Hamburg - Munich). There are also a number of large investment projects that aim to open high-speed origins and destinations (O\&Ds) that are already or may in the near future be contested by LCAs (for instance in Spain).

\footnotetext{
* Contact author. Goethe-Universität, Grüneburgplatz, RuW Gebäude, Hauspostfach 52, D-60323 Frankfurt/Main, Germany; email: gfriebel@wiwi.uni-frankfurt.de We thank the Editor Julian Wright, Aaron Gellman, Markus Ksoll, a referee and seminar participants at the "Second Railroad Conference at Northwestern” and at TU Berlin for their comments. The authors acknowledge the advice and research support of Deutsche Bahn. The views expressed remain those of the authors alone.

${ }^{1}$ See, for instance, Alderighi et al (2004), Franke (2004).
} 
Second, the European Commission has, in its White Paper (EC, 2001), declared the development of the rail sector a priority for sustainable development. Hence, as railroads have ecological advantages compared to other modes of transportation, the European Commission has the explicit goals of promoting railways and increasing their market share. Third, the Commission is committed to enhance intra-modal competition in the rail transportation market by liberalizing access to national infrastructures, first for freight traffic, and soon also for passenger traffic, to enhance its efficiency.

The issue of developing the rail sector is linked to the question of inter-modal competition. This is, in particular, the case as LCAs seems to be increasingly important. Yet, there are no data sets available that allow estimating the intensity of future competition between LCAs, network airlines and rail operators and about market outcomes. In such a situation, it is useful to investigate case studies in order to learn more about the functioning of what may in the future become an integrated European long-haul transportation market.

The case we look at is LCA entry in Germany. In late 2002, two LCAs opened 16 new routes in the course of only few weeks. Some of these origins and destinations (O\&Ds) were (and still are) in direct competition to routes of the Deutsche Bahn (DB), the incumbent rail network operator in long-haul passenger traffic. Using some unique turnover and pricing information, and based on market research data of DB with a team of the University of Münster (Grunberg et al, 2003), we document the impact of LCA entry on Deutsche Bahn and the incumbent air network provider, Lufthansa (LH). We look at their reactions to entry and argue that the different network constraints air and rail network providers are subject to may explain some of the differences in their reaction strategies.

Our main results can be summarized as follows: First, LCA entry appears to have much stronger effects than what one would expect given the measures of inter-modal price elasticities that exist in the literature. Turnover of Deutsche Bahn dropped drastically. Market research shows that air and rail traffic are close substitutes, in particular for trips of up to five hours. Second, the entry of LCAs forced DB to react. Looking at their price reactions on one origin and destination, it turns out that mimicking the price structure of LCAs is a quite effective way to regain competitiveness and to stabilize turnover, albeit on lower levels than before LCA entry. Third, DB only changed prices locally, that is, the overall price system remained unaffected. In contrast, Lufthansa, changed its entire price system, and introduced much lower prices for all intra-German O\&Ds and many European routes. Fourth, we argue that this type of asymmetric price reaction is owing to different technological constraints of rail versus air network operators. In general, transportation firms have high fixed costs, and their average costs are hence very dependent on load factors. This is particularly true for railroads, which would have a strong incentive to engage in aggressive yield management practices on contested O\&Ds. However, their network structure makes such strategies very costly: Rail networks have a fundamental disadvantage compared to airlines. They constitute an open system, in which passengers who travel on a train from A to B are free to enter and exit at any stop between initial origin and final destination. Hence, reducing the prices on the O\&D from A to B, may have severe yield effects on all O\&Ds that lie in between the contested line, and on those that include the contested segment. Therefore, while many railways already use yield management, it cannot be used as effectively as in air transportation which builds on a closed system. 
The next section provides some background on the development and the business model of LCAs. In particular, we compare LCA cost structure to network rail operators. Section 3 documents the entry of LCAs in Germany and the effect on DB's traffic. Section 4 describes the reactions of the network operators and some of its effects. It also provides estimates of substitution rates between train and LCA. Section 5 discusses the constraints railroads are subject to when carrying out price reactions. The concluding section summarizes and points to implications of this case study on regulation of intra- and intermodal transportation markets.

\section{$2 \quad$ Low-cost airlines}

The first low-cost airline entered the US market in 1971: Southwest Airlines began to operate flights between Dallas, Houston and San Antonio. The fleet rapidly expanded, and today Southwest Airlines is the largest domestic operator in the US. It has never operated at a loss, and many companies have tried to emulate its business model. As of today, there are 15 low cost airlines in the US, and estimates of the market share of low cost carriers in the US are estimated over 22\% (Mercer Consulting, 2002) and 24\% (Ito and Lee, 2003).

Europe's history of low-cost airlines is much shorter. The EU deregulated the airline market only in 1997, and the market share in EU countries differs between high singledigit numbers in, for instance, Germany and France, and 15\% in the UK (Eurocontrol, 2003). Figure 1 (all figures are in the Appendix) shows that Germany was among the markets with the highest growth in LCA market share. Many observers believe this to be a sign that Germany may enter a similar phase of rapid LCA growth as the UK did in 2001.

Figure 2 shows that since the beginning of 2001, the LCA market share in domestic airline transportation in Germany was slowly growing. At the end of 2002, it jumped from around 4\% to 8\%, when two companies, HapagLloyd Express and Germanwings started 16 new O\&Ds. The LCAs offered intra-German connections at truly competitive prices. On average they charged around 70 Euros, less than $40 \%$ of the average price of Lufthansa prior to the LCA entry, which was around 180 Euros.

What distinguishes LCAs from existing air and rail network operators? First, the LCA business model enjoys substantial cost advantages compared to incumbent airlines. The estimated advantage in terms of cost per available set mile (CASM) is between 25-30\% for domestic flights, and 40 to 60\% for border-crossing traffic (Binggeli and Pompeo, 2002). This is owing to higher resource utilization (especially of fleet), but also to lower labor costs (LCAs employ younger non-organized workers), cost-effective direct sales systems, younger and homogenous fleets that imply lower maintenance costs, and lower ground handling costs and landing fees (Franke, 2003). We will get back to the issue of cost advantages and disadvantages between rail and air transport later.

An additional advantage of LCAs is their flexibility. They can decide to operate on new origins and destinations (O\&Ds) without having to invest much in new infrastructure. As they often use the same types of plane and there is a high degree of international standardization across airports, the costs of reallocating assets from one O\&D to another are low. Direct sales instruments, in particular, the internet, allow for rapid price changes. Moreover, the price of one O\&D has little, if any, effects on the price of other O\&Ds served as there are no connecting services offered. 


\section{$3 \quad$ LCA entry and railways}

It is not easy to a priori estimate the effect of LCA entry. Inter-modal price elasticities here, between rail and air - provide some information. Such cross-elasticities are arguably imperfect measures for entry effects, because they measure the sensitivity of rail traffic, when the price of the inter-modal competitor increases or decreases. The case we look here, however, is the entry of an entirely new business model. Anyways, surprisingly little is known about the cross-elasticities between air and rail. In one survey (Oum et al, 1990), estimates are rather small - between 0.01 and 0.51 , but this is based on aggregated data and not some well-defined market. According to the Australian Bureau of Transport and Regional Economics data base referred to in IDEI (2003), the elasticities are - besides one potential outlier (1.12) - in the range between 0.04 to 0.36 . In general, it is believed that the elasticities between different modes are small in the short term, and potentially substantial in the long run only. Given these estimates, one should expect small effects of LCA entry on the rail network operator's traffic.

However, the LCA entry in Germany had a massive impact on rail traffic. To measure the effects of LCA entry on rail turnover and yield, consider first the magnitude of entry. Figure 3 provides some estimates for the size of business of some O\&Ds operated by LCAs compared to the size of DB's business on the same O\&Ds. Depending on the O\&D, LCAs business is up to $70 \%$ of DB's. More striking are the estimates of substitution rates provided by Grunberg et al (2003) and Meffert et al (2005) who surveyed a total of 2408 travelers at six German airports: Berlin, Dusseldorf, Hamburg, Hanover, Cologne-Bonn, Moenchengladbach. The researchers asked travelers about their choice if the LCA O\&D that they used had not been available: A share of $79 \%$ of the respondents would have used a different transport mode, 15\% would not have travelled at all, and 6\% would have travelled to another destination. Within the first group, 20\% would have definitely chosen rail transportation, and a further $13 \%$ would have considered rail transportation as an option. Figure 4 (from Grunberg et al, 2003) shows the breakdown by some O\&Ds. The lower bound is the proportion of customers who would have chosen rail for sure, the upper bound represents customers who would have considered rail as an option. Figure 5 (Grunberg et al, 2003) shows the breakdown by hours of rail traffic. There is a strong correlation between rail travel times and substitution rates, on shorter distances LCA substitution is highest. Notice that these numbers imply a price elasticity that is far above the estimates from other studies. Figure 6 shows the effects on DB's turnover on one domestic line, Hamburg-Cologne. On this O\&D, DB operates trains of different quality and speed. The fastest and most comfortable train is the Metropolitan Express, a premium product that targets mainly business travelers and that travels non-stop between two of the main commercial and industrial centers in Germany, the Ruhr Valley and Hamburg. HapagLloyd Express entered on December 3rd on this O\&D. As the graph shows, the turnover of $\mathrm{DB}$, measured in passenger kilometers decreased immediately and reached a $30 \%$ lower volume after three months. Some international O\&Ds of DB suffered similarly, as the second panel on Figure 6 shows. DBs traffic volume from Hamburg to Vienna decreased by more than half. Figure 7 provides another estimate of the effects of LCA on DB's traffic, here on the O\&D from Cologne to Berlin, another main axis of passenger rail transportation.

It is difficult to exactly quantify the effect of LCA entry on all of DB's traffics, as the entry of LCA correlated with other events, in particular, a hard winter that led to problems 
with punctuality. An additional confounding factor was a new DB pricing system that many customers perceived negatively. It is important to note that these changes were not related to the LCA entry, but had been decided before. Furthermore, the Metropolitan Express between Cologne and Hamburg was not affected by these price changes as it operates as a separate company within the DB Holding. Nonetheless: taken together, the evidence seems to indicate that rail traffic has been highly sensitive to LCA entry, in particular, for trips of up to five hours. These effects are much stronger than what one could expect given the low estimates of cross-elasticities from previous studies.

\section{$4 \quad$ Reactions of network operators: constraints and their implications}

Shortly after LCA entry, Lufthansa (LH) reacted by an overhaul of their pricing system. The company introduced a new lead price of 92 Euros for all O\&Ds within Germany and some of its European connections (UK, Austria and Switzerland). This pricing system is fixed in medium term, but the available contingent of seats in any price category can be adjusted to the strategic needs. That is, Lufthansa disposes of a flexible yield management that allows the company to react to new entries or price changes by adjusting the quantities of seat in different price categories. While we do not know the precise effects of these changes on turnover and yield for Germany, Lufthansa's turnover in Europe during the first six months of 2003 (after LCA entry) compared with the first six months of 2002 decreased by $6.4 \%$ and the yield decreased by $11.8 \% .^{2}$

The reactions of Deutsche Bahn differ from the ones of Lufthansa: rather than changing its price and seat contingent system, $D B$ only reacted on some O\&Ds. More precisely, DB changed the prices of the Metropolitan and of night trains, because they are not priced within the general DB pricing system. Figure 8 compares the price system for the Metropolitan Express from Cologne to Hamburg. Prior to LCA entry, the cheapest price was 50 Euros and the most expensive price 79 Euros. Here, the lowest price was "weekend special", requiring Saturday night stay and five-day advance purchase; the next price was "return special", requiring return purchase and three-day advance purchase; the full fare had no restrictions. DB then changed the prices for this train, offering the cheapest ticket at 19 Euros, and four more prices, up to 79 Euros. New prices are all oneway without any restrictions - only quotas regulate availability, exactly like in airline yield management. The second panel of Figure 8 shows that this reaction had massive effects and that the traffic volume reached similar levels than before the entry. However, the yield during the nine months after the price reaction dropped by $23 \%$ compared to the year before LCA entry. Figure 9 shows that the fare change involved a stabilization of turnover. This implies a substantial drop of the average price on the O\&D.

This example shows that an incumbent rail operator can - in principle - react by changing its prices, and that this can stabilize the situation in terms of traffic volume. It goes along, however, with substantial revenue losses. Yield management through innovative price systems also plays a crucial role for the cost side of the business. To see why, consider Figure 10 that qualifies the view that LCAs always have cost advantages compared to rail network operators. It shows that the costs of LCAs in terms of CASM are not lower than the one of the rail network carrier Deutsche Bahn. Deutsche Bahn's CASM

\footnotetext{
${ }^{2}$ http://konzern.lufthansa.com/en/html/presse/pressemeldungen/index.html
} 
is comparable to Ryanair's and lower than EasyJet's. There are strong economies of scale in railroads, in particular, economies of density, that is, the marginal costs per passenger mile at given network size decreases in traffic volume. ${ }^{3}$ However, Figure 10 also shows that at low load factors, it is impossible for a railroad to operate in the most cost-effective range. Hence, it appears a good strategy of a rail operator to engage in aggressive yield management practices upon entry of an LCA, in order to increase or at least stabilize its demand.

This raises the question of why such reactions would be infeasible for all of the affected O\&Ds. To answer this question it is useful to first look at the network structure of the three main actors, LCAs, Lufthansa and DB. LCAs mainly operate on point-to-point connections. Railroad and airline incumbents operate networks. Figure 11 depicts the polycentric network structure of both Lufthansa and DB. This type of network structure imposes important constraints on the strategies of the incumbents. ${ }^{4}$

First, LCAs can change their schedules at short notice - provided that the airports they want to connect have slots available. A rail network operator cannot change its network in the short-term as this requires massive, expensive and time-consuming infrastructure investments. It is also difficult to change the schedule of traffic, given a physical network of tracks. Adding or taking away a connection, or increasing or decreasing the frequency on one connection potentially affects many other connections. Schedules are usually planned with long lead times and they are the result of complicated optimization procedures. Often, there are a number of bottleneck tracks in a network that impose binding constraints that need to be taken into account for any short-term adjustment. This is to a smaller extent also true for the connections of an air network carrier who when planning any change in schedule must take into account the effects on connecting flights.

Leaving problems of network management aside, it is important to note that the price strategies of railroads are subject to a set of constraints that do neither exist for LCAs nor for air network carriers. As pointed out before, railroads enjoy cost advantages over most airlines, provided that they can reach sufficiently high load factors. Hence, if an entrant attacks a railroad on a given $O \& D$, the railroad should be expected to reduce its price in order to increase the load factor and average costs per passenger. However, this is not as easy as it seems.

Figure 12 illustrates the problem. Consider the point-to-point connections of LCAs. They represent a closed system: a customer who boards a plane from, say, Paris to Cologne cannot disembark at a place between the two points. This is not true in a rail network: it is very difficult to prevent customers from getting off a train in Brussels given that most if not all trains between Cologne and Paris have a stop in that city. In a closed system, it is possible to use aggressive prices, while in an open system, there is a risk of "cannibalization". When the operator reduces the price on the connection from Paris to Cologne, it must take into account the potential yield effect for the legs from Paris to Brussels and Brussels to Cologne.

Figure 13 illustrates a real-world example. The LCA on the route Cologne-Berlin has a lead price of 19 Euros. The curve represents the 50\% discount fare that is available when

\footnotetext{
${ }^{3}$ For an overview over the literature on the economies of scale in the railroad industry see IDEI (2003). Notice that there is rather inconclusive evidence concerning economies of size, that is, the development of costs when, at given density, network size increases.

${ }^{4}$ It is interesting to note that the case is different for the long-haul network of French railroads, which is monocentric.
} 
the customer holds a subscription to BahnCard, which costs $200 €$ für second class; $400 €$ for first class per year. This fare is also available in limited quantities for early booking with weekend restrictions. Consider that DB would reduce its price to Berlin to the same level of the LCA. This would make it attractive to customers on many segments between Cologne and Berlin to buy a ticket to Berlin, rather than to their actual destination. To be consistent, DB would have to quote the price to Berlin to any customer for whom that ticket would be cheaper than the ticket for the segment they want to travel on.

Railroads are also subject to the problem of "sum of locals" ticketing. Consider a rail customer who travels from A to D. Suppose that there is an LCA entrant in a segment B to $\mathrm{C}$ that is part of the A to $\mathrm{D}$ connection. ${ }^{5}$ The rail operator would like to reduce the price on the $\mathrm{B}$ to $\mathrm{C}$ connection to stay competitive. However, this would involve yield erosion on the A to D connection: customers could book one ticket from A to B, another from C to D, at the usual prices and a third ticket from $B$ to $C$ at the new, lower price. Network airlines are subject to similar problems, hence do not allow "sum of locals" ticketing. They can reject passengers who have such tickets or refuse through-checking of baggage. For railways, it is much harder to avoid the problem, as it is both difficult to detect "sum of locals" and - if detected - to send customers off the train. LCAs are not subject to the problem, as they usually do not operate connecting flights.

The heart of the above problem is the presence of customer asymmetric information. ${ }^{6}$ When designing its tariff structure, the rail operator must take into account the "incentive compatibility constraints (ICs),"7 of customers. In our case, the tariff structure satisfies the ICs, if a customer who plans to travel on the intermediate legs (Paris to Brussels, Brussels to Cologne) has no incentive to buy a ticket Paris to Cologne. That is, the price between Paris and Cologne must be larger as the price of any of intermediate O\&D's. Otherwise, the railroad operator would lose some of its yield on the intermediate O\&Ds. It may be the case that the lost yield on the intermediate O\&Ds is more than compensated by gains on the O\&D Paris to Cologne, in which case the rail operator may decide to deliberately violate the IC. But, in general, the IC imposes a floor for a price change. This severely constrains the capability of a network railroad to react to a low-price entrant on a given O\&D. As pointed out, an airline network operator is not subject to the same ICs, which gives them more flexibility concerning their price reactions.

In order to relax the IC of customers, the railroad operator may think how to screen customers according to their points of origin and destination. It may decide to check at any train station whether a passenger has travelled between the points they hold a ticket for and, if not, to make them pay the difference (and maybe also a penalty). Another potential

\footnotetext{
${ }^{5}$ A realistic example is Aachen (city A) to Rostock (D) with Cologne (B) and Berlin (C).

${ }^{6}$ For the state of the art of incentive theory in regulated markets, see Laffont and Tirole (1992).

${ }^{7}$ In the theory of contracts, the "incentive compatibility constraint” defines a constraint a principal has to take into account when designing optimal contracts for agents that possess private information. In such situations, the principal designs a menu of contracts for each type of agent (here "type" describes the sort of private information an agent has, for instance, whether they have high or low valuation for a good the principal sells), and agents select their preferred contract. One can show that in such a situation it is usually optimal for the principal to make the agent reveal their private information, that is, in equilibrium each agent chooses the contract that has been designed for their type. However, in order to do so, it must be true that the agent cannot lose from accepting the contract designed for their type, that is to reveal their information, rather than pretending to be a different type. This condition describes loosely the incentive compatibility constraint we refer to. The theory of contracts has been widely applied for problems of regulation, procurement and competition policy, see Laffont and Tirole (1992).
} 
system is to sell tickets for any segment on a given O\&D at the price of the most expensive segment and to reimburse passengers who prove that they have travelled on less expensive segments. While the first possibility is easier to implement administratively, it may involve resistance of customers. The other solution may be harder to implement, but as it has the nature of a bonus, rather than a penalty, may prove to be more popular.

The discussion above has been based on the notion that customers are fully rational and that the sales agent always quotes the best price for the customer. Full rationality of customers may, however, not always be the case. In modern transport markets, pricing systems are often very complex; it takes even an experienced traveller some time and effort to learn about the best offers in the market. There is hence a benefit in using aggressive lead prices to communicate with customers and to attract them, although the communicated prices are lower than those that are actually available to most passengers. Nonetheless, customers with significant information gathering costs will be susceptible to this effect. Railways are unable to match these lead prices owing to the pricing consistency considerations we have highlighted before. As a result customers perceive rail as a more expensive transport option than LCAs when in fact they are not. Grunberg et al (2003) have documented this quite clearly: in their survey of LCA passengers they find that there was a perceived price disadvantage of rail $v$ air of $42 \%$, while in reality there was an average price advantage of $28 \%$ in favour of rail transport. We yet have no full understanding of the source of the massive misperception of rail prices, but it appears that these misperceptions are a widespread phenomenon. It is interesting to note in this context that other industries such as car rental and hotels have more recently discovered the appeal of aggressive lead prices, presumably for similar reasons.

\section{$5 \quad$ Concluding remarks}

We have documented the effect of LCA entry in the German market. This type of intermodal competition affected railroad origins and destinations (O\&Ds) in a substantial way. After the entry of LCAs, traffic volume of the incumbent rail operator, Deutsche Bahn, decreased by up to $50 \%$ on relevant O\&Ds. The price reactions of DB on one O\&D were effective in increasing turnover and stabilizing yield, albeit on a lower level than before LCA entry. However, compared to airlines, railroads are subject to important constraints severely limiting systemic price reactions such as aggressive, permanent lead prices.

Our case study shows that inter-modal competition has more bite than what is usually considered. This is important for the design of regulatory schemes, for the liberalization of national railroad markets, and the creation of an integrated European transportation market. In particular, it is misleading to look at regulation of railroad markets in an isolated way, rather than considering the interplay of different modes on a given market. While the market for long-haul passenger traffic in Europe has traditionally been dominated by flag carriers (and to lesser extent, national rail networks), one can expect that it will be heavily contested by LCAs in the future. These LCAs can act and react swiftly. Incumbent airlines also have a rather high degree of flexibility, but owing to their network structure, railroads are much less flexible and hence more vulnerable.

When designing reforms for railroads, regulators should hence take into account that measures that may be increase intra-modal competition to some extent may, by the same 
token, weaken rail network operators in the inter-modal competition with LCAs and flag carriers.

To better understand the impact of LCA entry and the reactions to it, it should be noted that the airlines have been affected by deregulation much earlier than railroads. Beginning with 1992, Lufthansa has gone through an ambitious restructuring program in the course of which the airline was privatized step by step, and a number of activities were spun off. The European airline market was deregulated in 1997, which led to massive changes. The restructuring process of Deutsche Bahn started later (in 1994) and initially took place in a more regulated environment than the airline market. The German market has, however, been opened to competition on track, and the long-haul market is neither regulated nor subsidized. The European market - while still rather strongly regulated - will follow. The first (mostly partial) reforms that were undertaken already show effects Friebel et al (2004) show that national restructuring and reform activities and the opening of national markets have had efficiency-enhancing effects on the railroad industries. Deutsche Bahn has been among the national operators with the larger efficiency gains through the last decade. This is also reflected in an increase of financial performance; DB estimates the effects of its cost-cutting effects to be around 100 billion Euros since 1994.

Cost-cutting seems a necessary but not sufficient condition for railroads to be competitive in the inter-modal transportation market. Intensifying inter-modal competition requires efforts to learn about yield management and the constraints it is subject to. This paper shows that it is possible to react, but also that it is more difficult for railroads than for airlines. Given the existence and intensity of inter-modal competition and the severe network constraints of railroads, it must be expected that most policies that are designed to increase competition in intra-modal markets also have effects in inter-modal markets. Put differently, it will become increasingly important for regulators to think about the definition of relevant markets when designing reforms.

\section{$6 \quad$ References}

Alderighi, M., A. Cento, P. Nijkamp and P. Rietveld (2004) "The Entry of Low-Cost Airlines: Price Competition in the European Airline Market," Tinbergen Institute Discussion Papers, 4: 73-74.

Binggeli, U. and L. Pompeo (2002) "McKinsey on LCCs: A European Goldrush?” Aviation Strategy, June, 16-18. www.mckinsey.ch/_downloads/aboutus/Aviation_Strategy_06.02_LCCs.pdf

Eurocontrol (2003) “The Recent Evolution of Low-cost Airlines’ Market Share,” May 27: 3. http://www.eurocontrol.int/statfor/analysis/43\%20Low-cost\%20study\%20v10.pdf

Franke, M. (2003) "Dawning of a New Airline Business Model - New Service Offerings for a Changed Demand,” Presentation at Hamburg Aviation Conference, Feb 13.

Franke, M. (2004) “Competition between Network Carriers and Low-cost Carriers Retreat Battle or Breakthrough to a New Level of Efficiency?” Journal of Air Transport Management, 10: 15-21. 
Friebel, G, M. Ivaldi and C. Vibes (2004) "Railway (De)Regulation: A European Efficiency Comparison,” February. http://ssrn.com/abstract=505302

Grunberg, B, H. Meffert, and J. Nießing (2003) “Low-cost Airlines,” Market Research for Deutsche Bahn.

IDEI (2003) Report \#1 on Passenger Rail Transport: “The Economics of Passenger Rail Transport: A Survey,” Prepared by P. Seabright.

Ito, H. and D. Lee, (2003) "Low Cost Carrier Growth in the U.S. Airline Industry: Past, Present, and Future," Discussion Brown. http://www.brown.edu/Departments/Economics/Papers/2003/2003-12_paper.pdf

Laffont, J.-J. and J. Tirole (1993) A Theory of Incentives in Procurement and Regulation. MIT Press: location of publisher.

Meffert, H., J. Niessing and B. Ballensiefen (2005) "The Market Entry of Low Cost Airlines in Germany - Potential Threats to the German Railways and Recommended Counter Strategies,” (in German), Glasers Annalen, 129: 68-74.

Mercer Management Consulting (2002): "Impact of Low-Cost-Airlines - Summary of a Mercer Study," http://www.mercermc.com/Perspectives/Specialty/MOT_pdfs/Lowcostairlines.pdf

Oum, T. H., W.G. Waters, and J. S. Yong (1990) “A Survey of Recent Estimates of Price Elasticities of Demand for Transport,” Working paper WPS 359, The World Bank.

\section{$7 \quad$ Appendix: Entry of Low Cost Airlines in Germany}

The appendix which follows contains all the figures cited in this paper. 


\section{Figure 1: LCA growth rates in Europe}

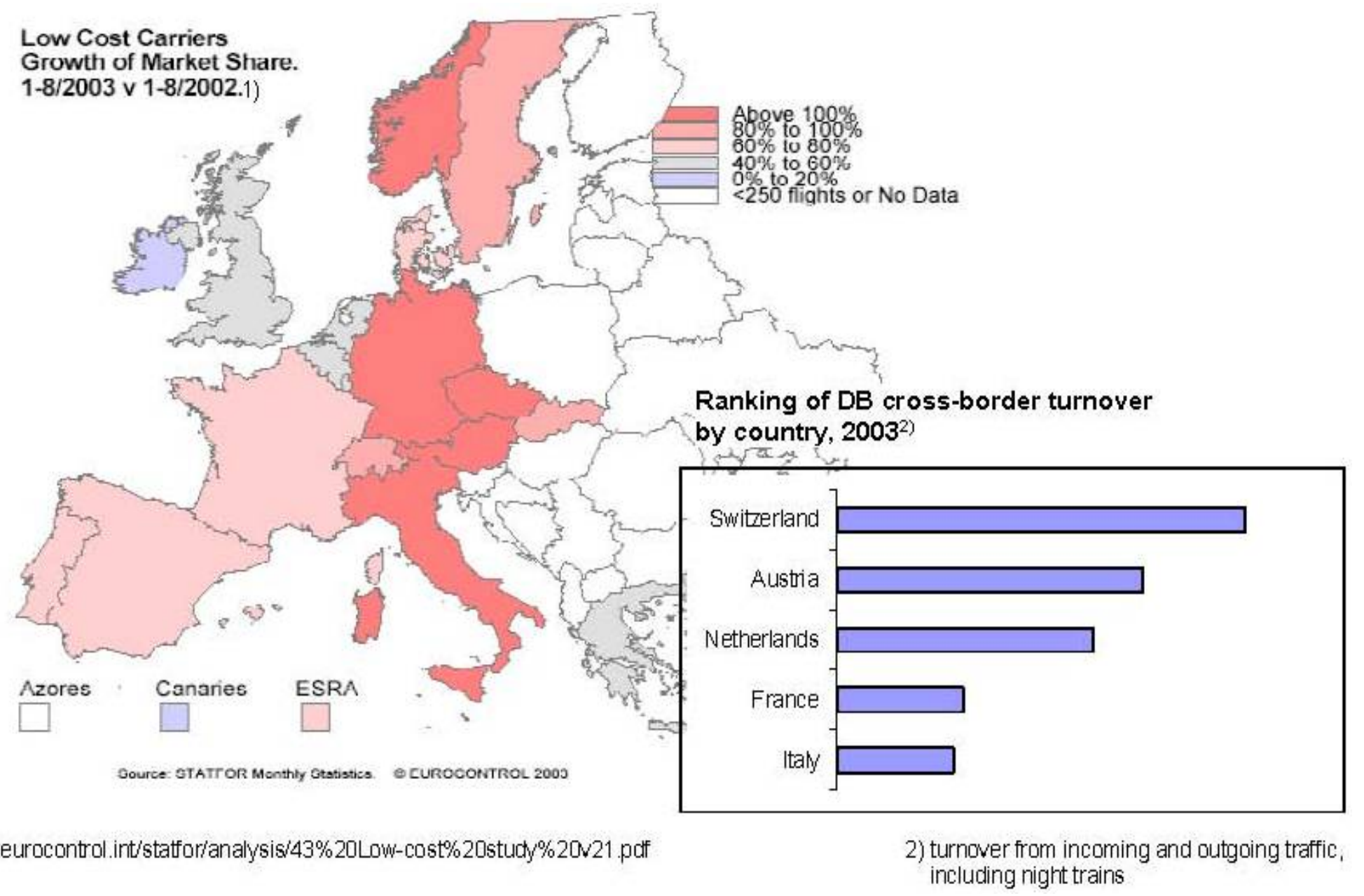

1) http://ww'w eurocontrol.int/stafforlanalysis/43\%20Low-cost $\% 20$ study $\% 20 \mathrm{v} 21$.pdf including night trains 


\section{Figure 2: LCA-growth rates France, Germany, UK}

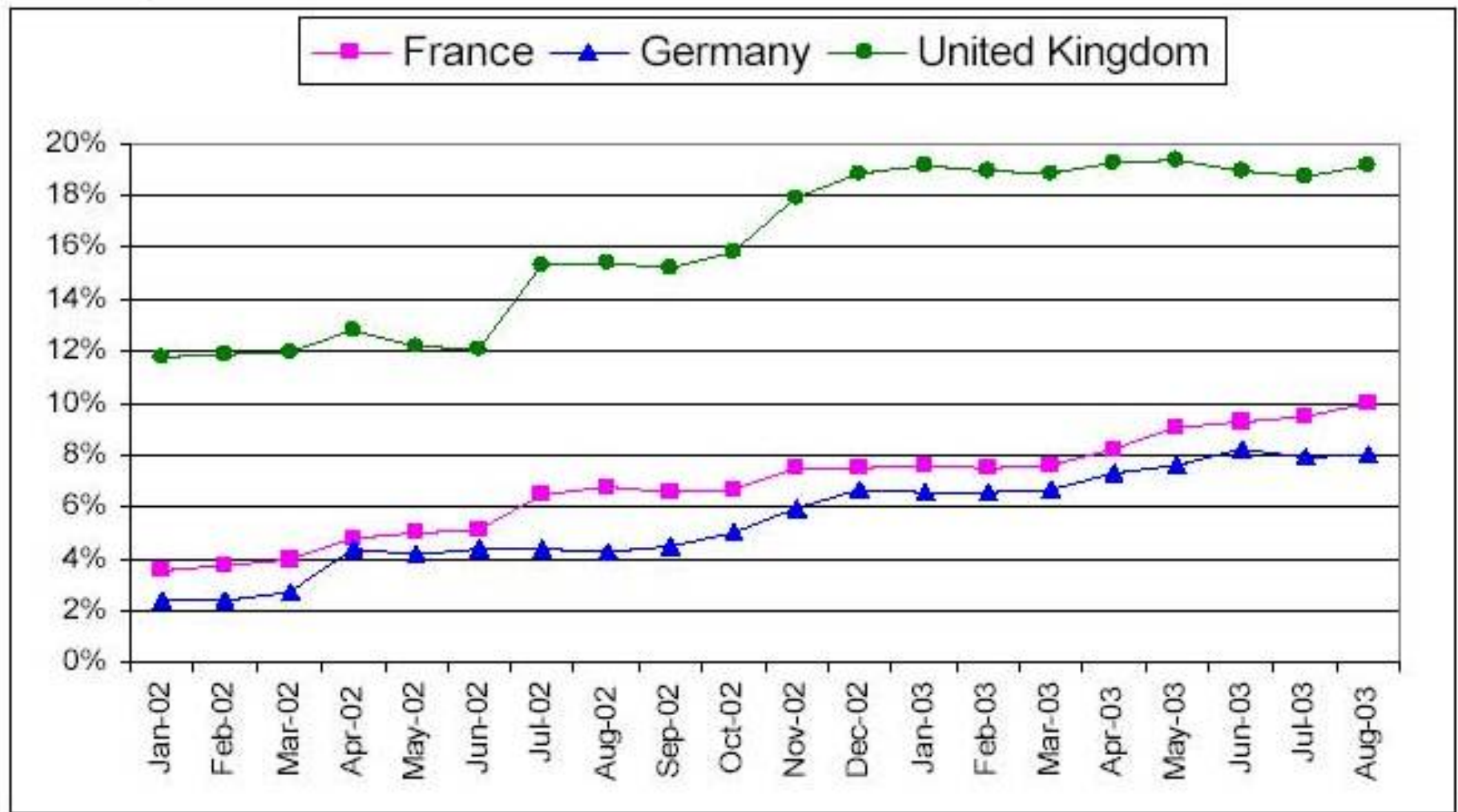

Source: http://www.eurocontrol.int/statfor/analysis/43\%20Low-cost\%20study\%20v21.pdf; for US: http://msnbc.msn.com/id/4664730/ 
Figure 3: Size of LCA business compared to DB; specific O\&Ds

\section{Passengers LCA / LH Low Fares vs. DB}
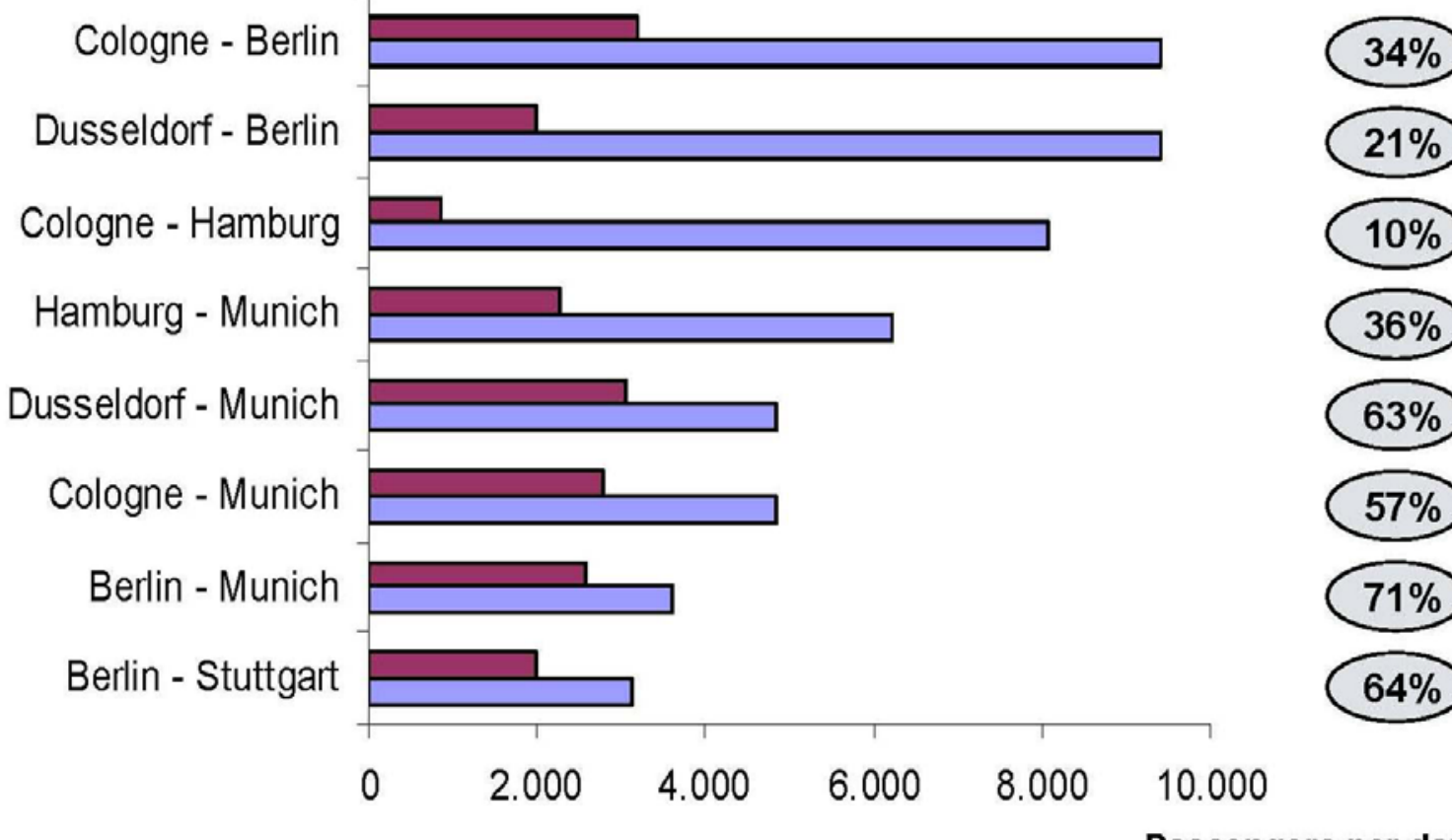

Airline volume as a

volume

口 LCA / LH-Low Fares

口DB (direct only)

Passengers per day

(both ways) $^{\star}$ 
Figure 4: Substitution rates between rail and LCA

\begin{tabular}{|c|c|c|}
\hline \multirow[b]{2}{*}{ Route } & \multicolumn{2}{|c|}{ Direct Substitution* } \\
\hline & $\begin{array}{l}\text { Would have } \\
\text { chosen rail }\end{array}$ & $\begin{array}{l}\text { Would have } \\
\text { considered rail }\end{array}$ \\
\hline Domestic $(n=1186)$ & $18,5 \%$ & $33,5 \%$ \\
\hline Berlin-Cologne $(n=429)$ & $21,2 \%$ & $36,4 \%$ \\
\hline Berlin-Munich ( $n=201)$ & $12,1 \%$ & $25,1 \%$ \\
\hline Hamburg-Cologne ( $n=163)$ & $23,5 \%$ & $38,2 \%$ \\
\hline Dusseldorf-Berlin ( $n=133$ ) & $20,1 \%$ & $36,7 \%$ \\
\hline International ( $\mathrm{n}=986$ ) & $3,9 \%$ & $10,9 \%$ \\
\hline Airports $w /$ revenue $>€ 100.000,-(n=560)$ & $5,5 \%$ & $14,9 \%$ \\
\hline to Vienna $(n=123)$ & $5,7 \%$ & $15,5 \%$ \\
\hline to Zurich $(n=104)$ & $10,9 \%$ & $26,8 \%$ \\
\hline
\end{tabular}


Figure 5: Trip duration and substitution rates

\section{"What proportion of LCA-travollors would have chosen the train instead?"}

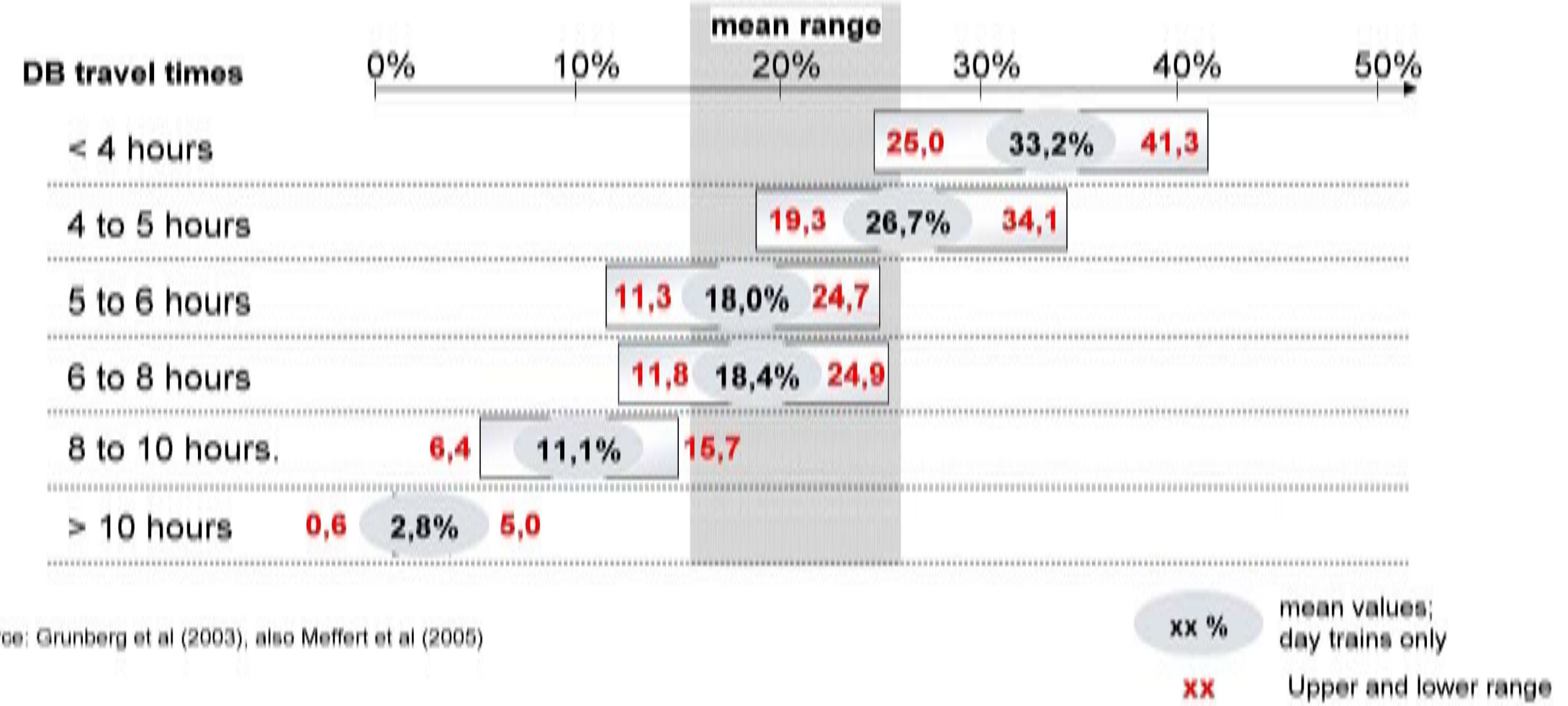


Figure 6: Effects of LCA entry on rail volumes; specific O\&Ds

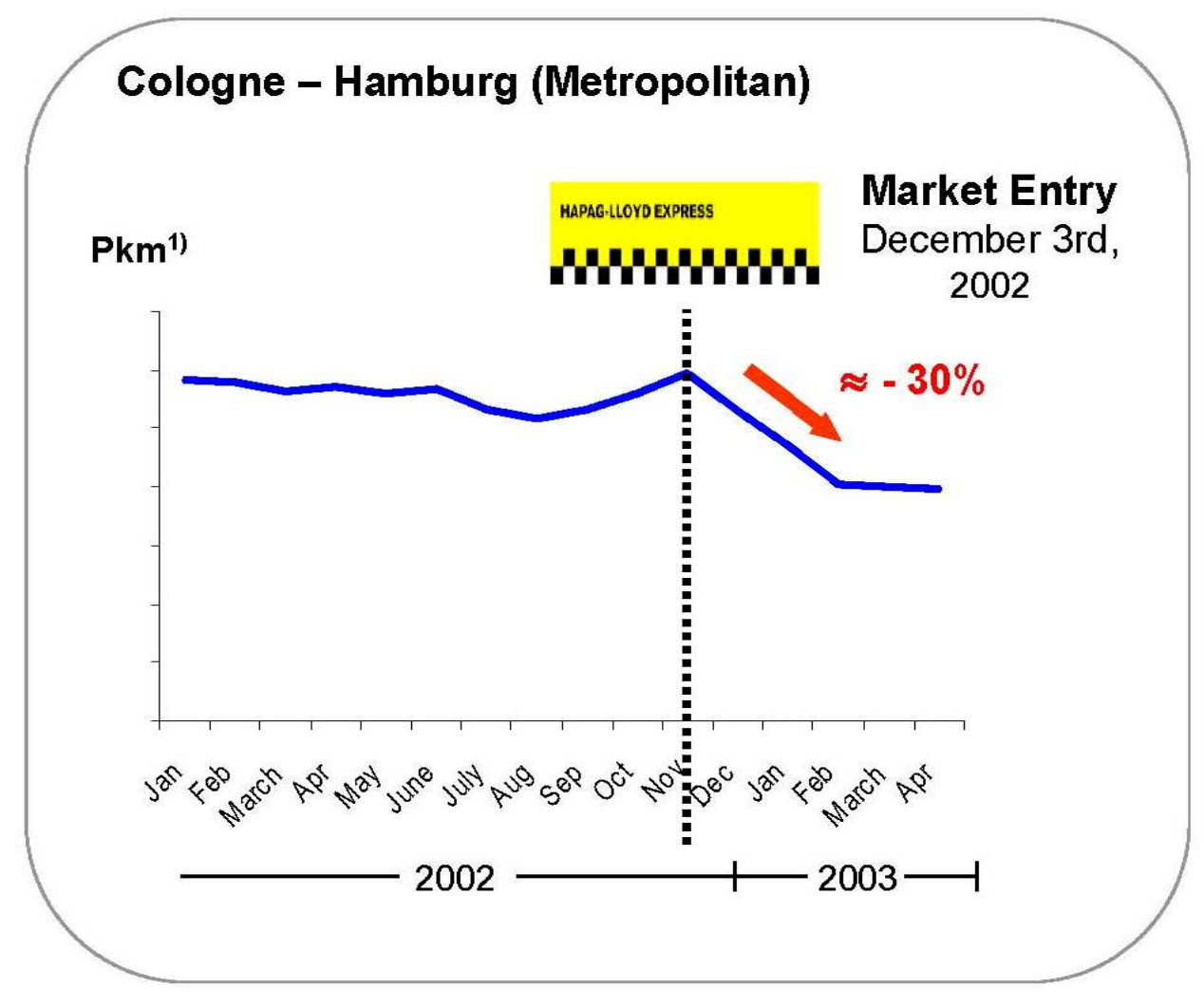

\section{International Destinations}

\# of Travellers

(01-04/2003 vs. 01-04/2002)

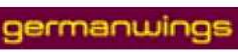

Cologne -

Vienna

$-56,8 \%$

1) 3 months - moving average; Source: $D B$ data 
Figure 7: Rail demand decline and LCA entry; Cologne-Berlin

In Mio. revenue-km/month

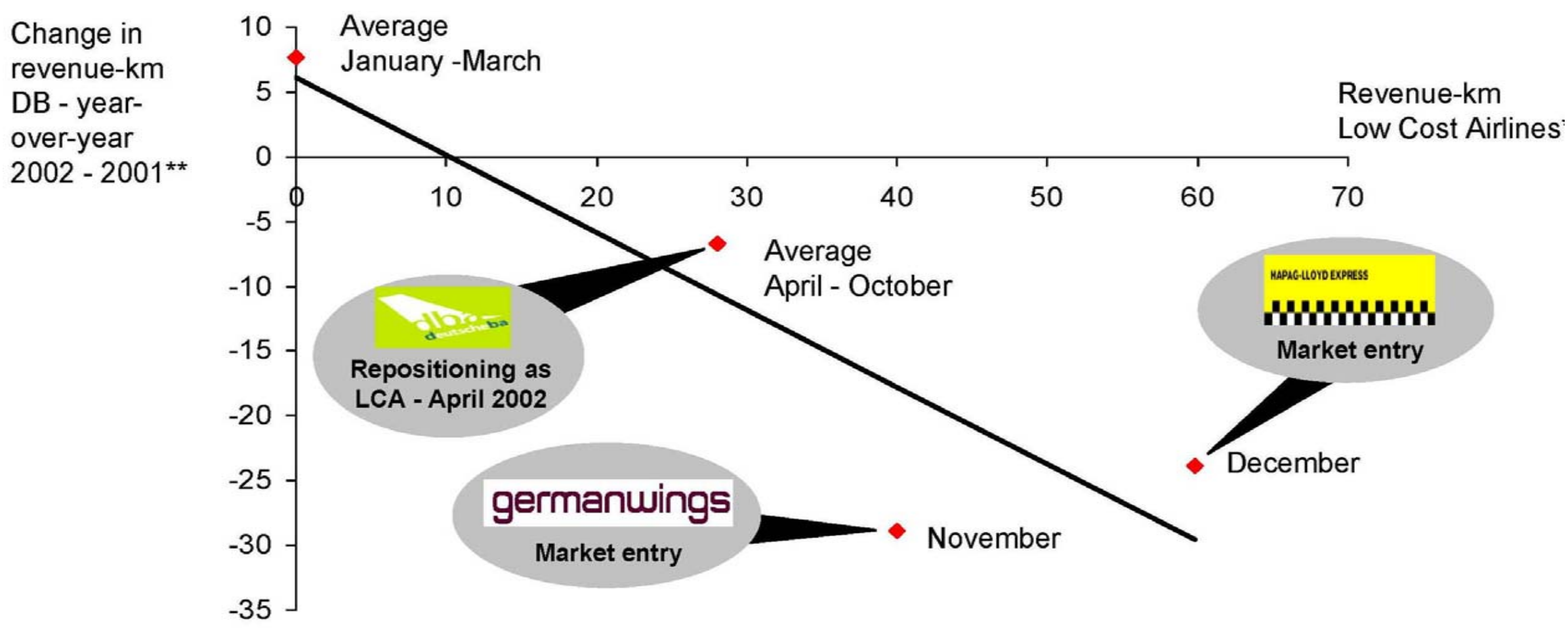

Calculated based on LCA-seat-km and assumed $80 \%$ load factor; Source: DB data 
Figure 8: Change of the pricing system for Metropolitan (Cologne-Hamburg) and effect on rail demand

Pricing Approach before and after LCA-entry

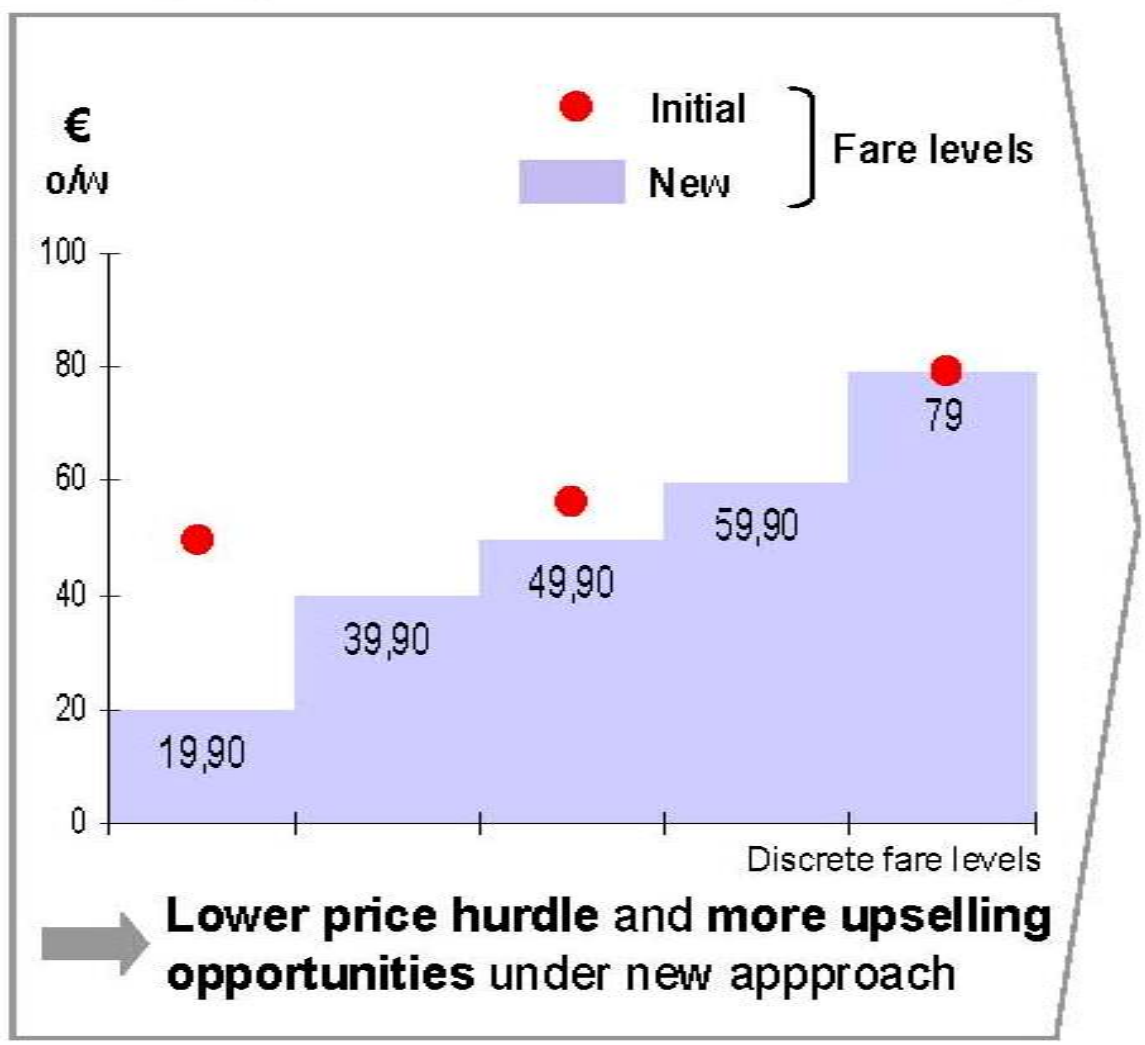

Source: "whw met.de - all fares are "Traveller Class"; BahnCard rebate $25 \%$

Old Pricing: Weekend Special; Return Special (both fares require rit purchase; Full Fare (all each way)
Demand

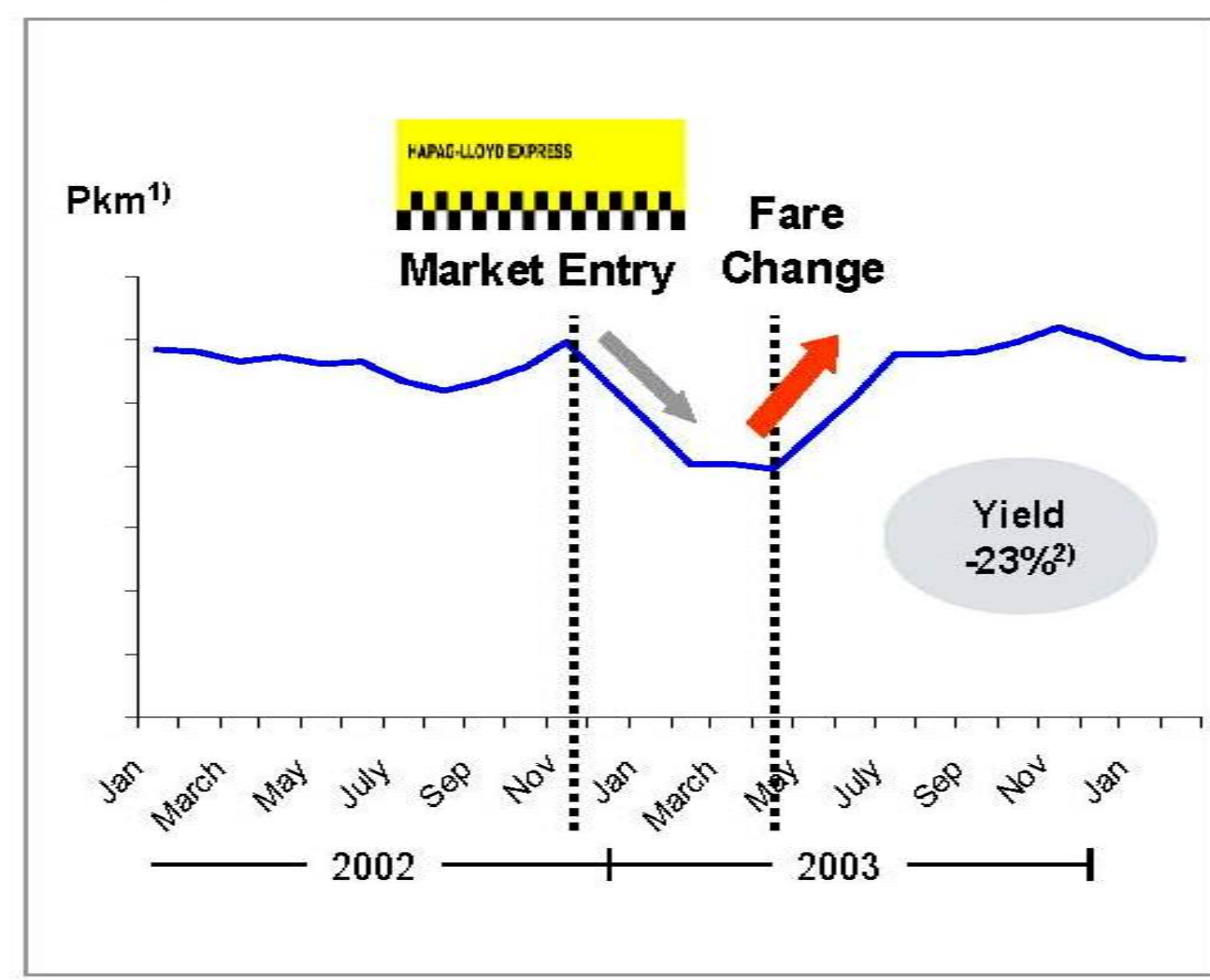

1) 3 months - moving average

2) $05-2002-04 / 2003$ vs. $05 / 2003-02 / 2004$ 
Figure 9: Effects of changed pricing system on revenue; Cologne - Hamburg (Metropolitan)

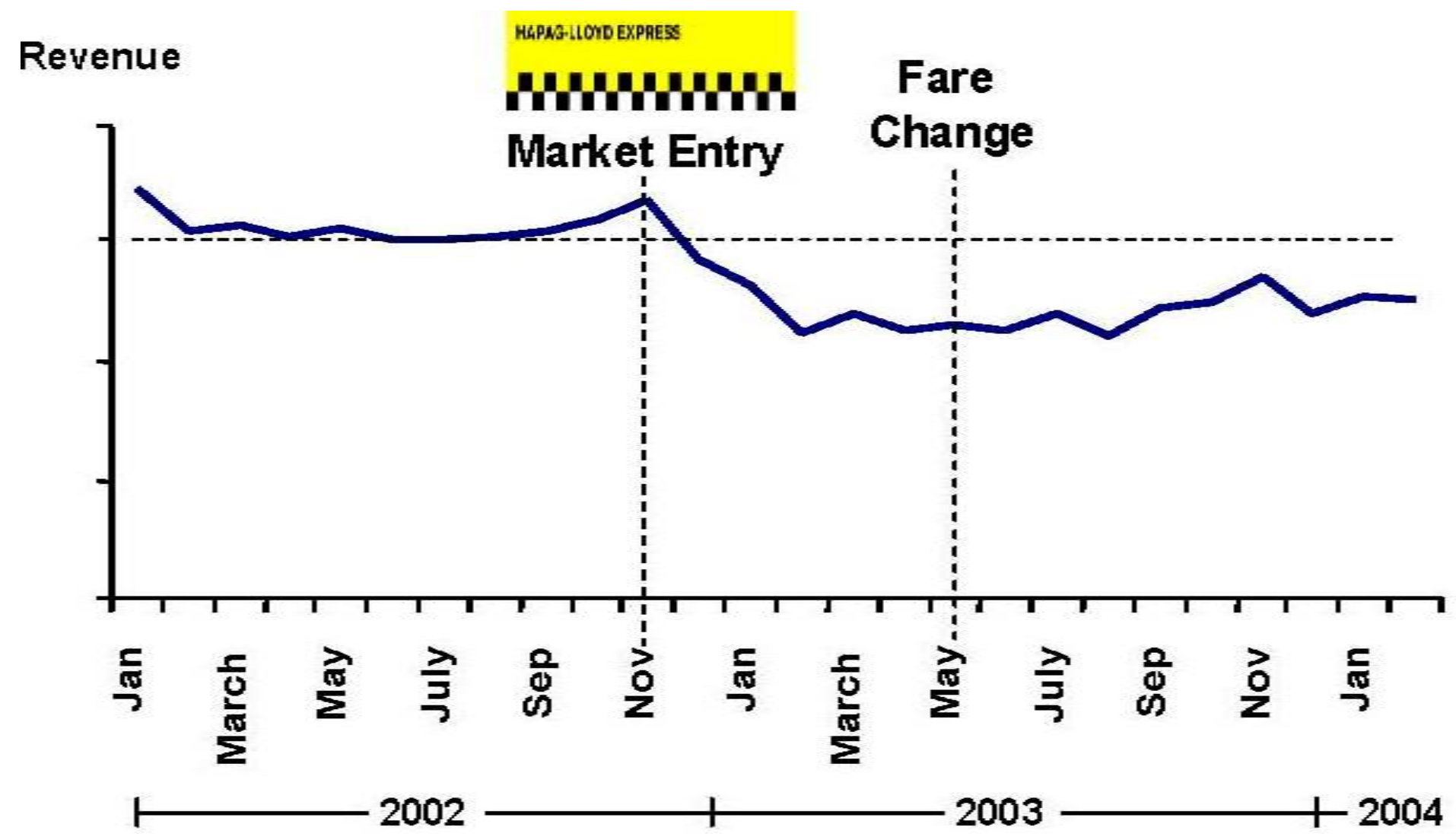


Figure 10: Effects of load factor differential on rail cost competitiveness; DB v some airlines

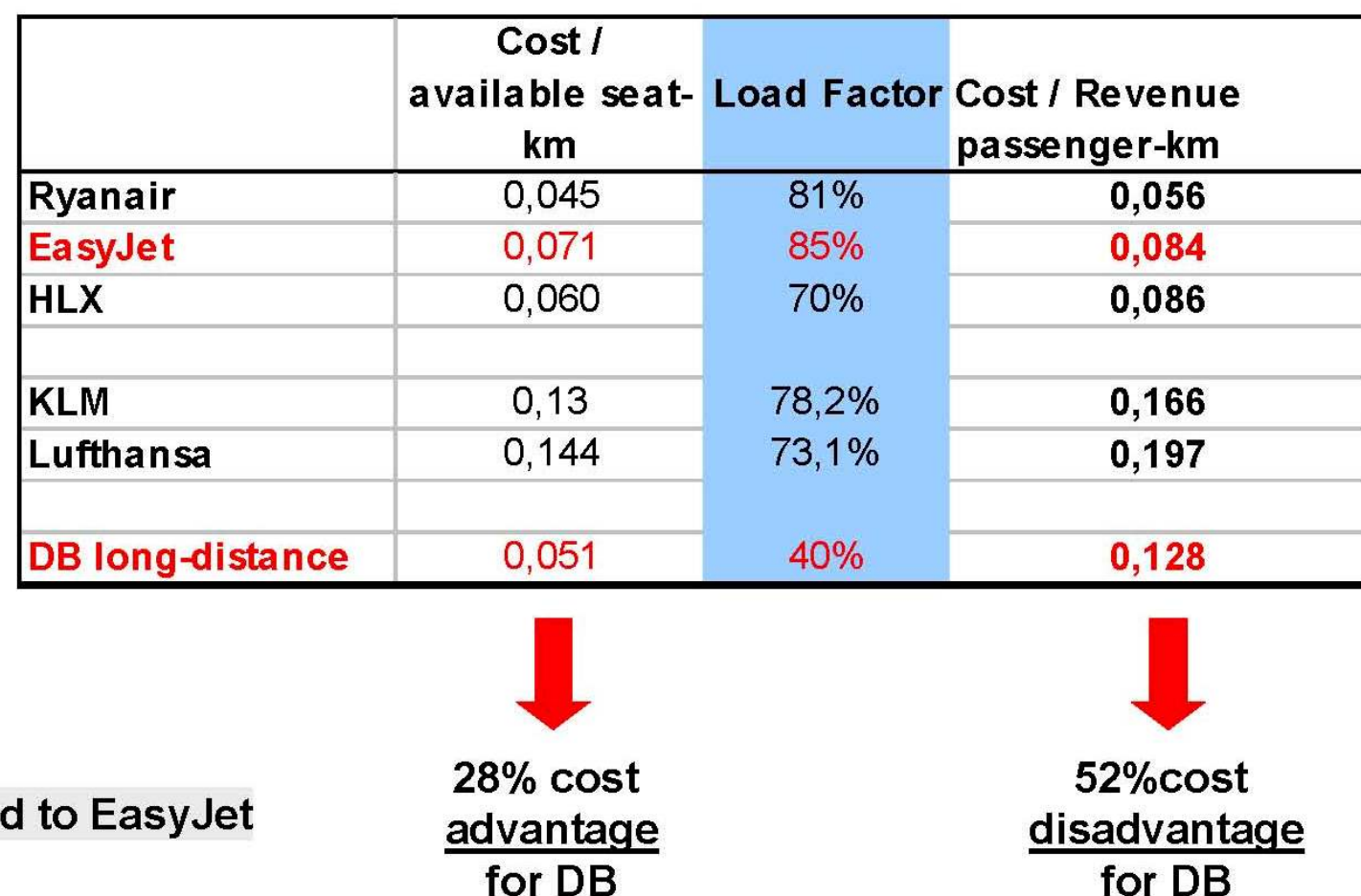

EasyJet cost data: Urs Binggeli / McKinsey: "Revolutionary or just Specialist - The low-cost concept in Europe" Presentation at 6th Hamburg Aviation Conference, 13. Feb. 2003

Load factor: http://www. easyjet.com/common/img/2004-05-05 interimPresentation. pdf

DB cost data: http://www.db.de/site/shared/de/dateianhaenge/berichte/geschaeftsbericht_2003_fernverkehr.pdf

Load factor: http://www.bahn.de/konzern/holding/umweltschutz/die_bahn_klimaschutzziel.shtml 
Figure 11: Network structures of DB and LH

\section{Lufthansa's domestic network}

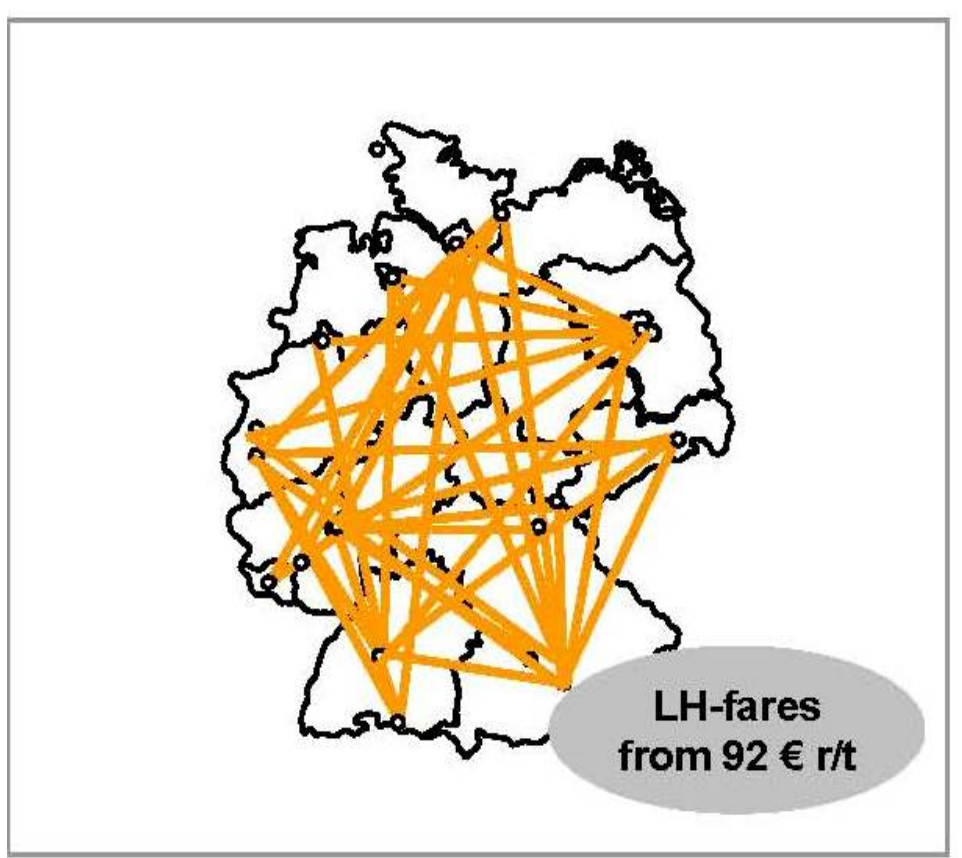

Domestic network of DB

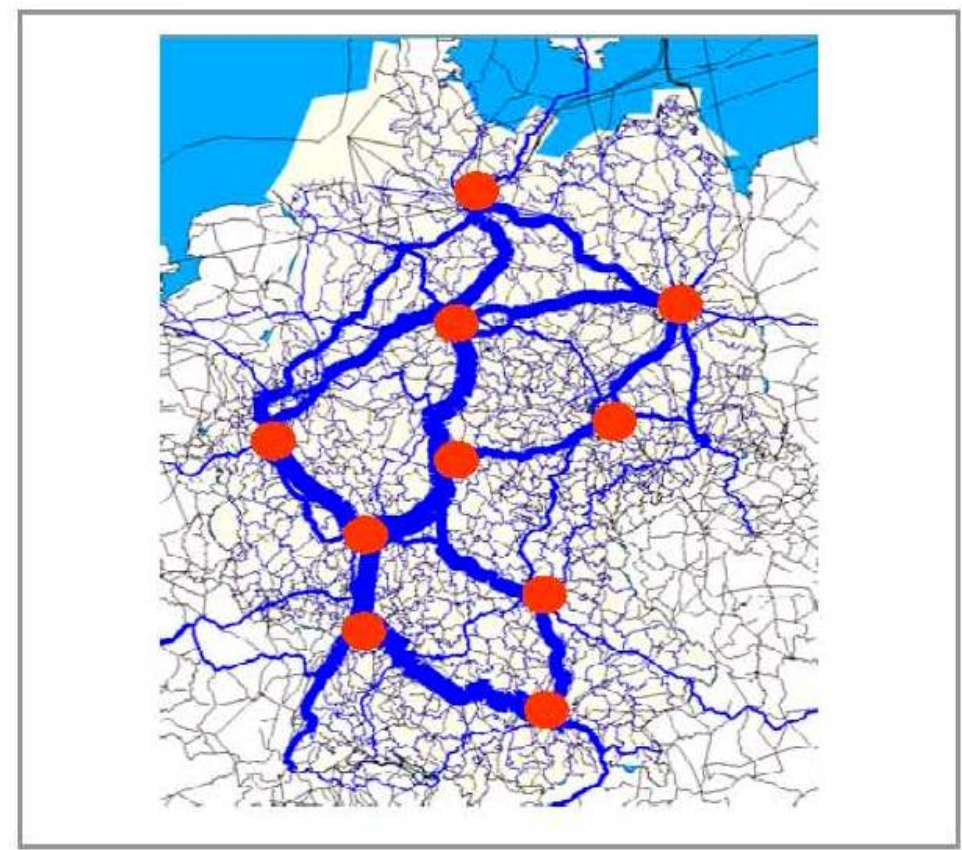


Figure 12: Constraints of rail network operators - an example

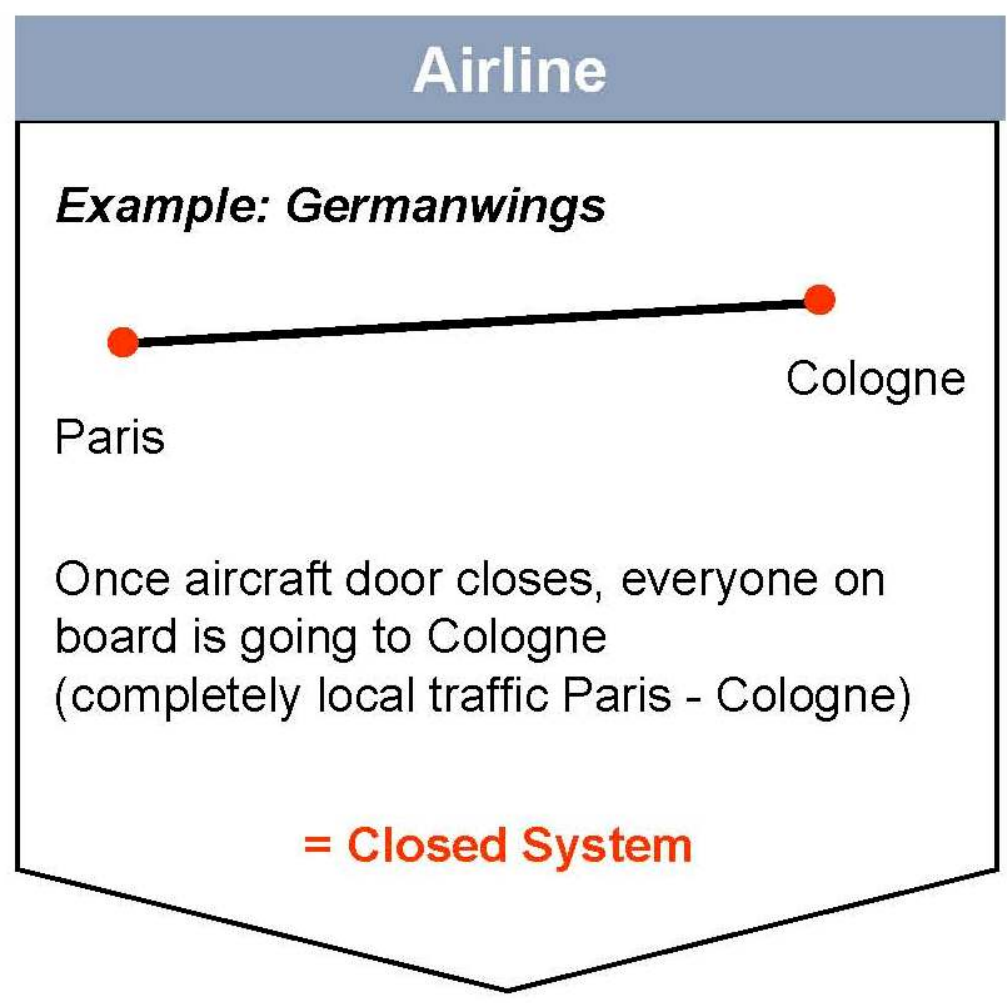

- Any pricing activity has strictly local effects

- Aggressive pricing can be used to attract more passengers and raise load factor

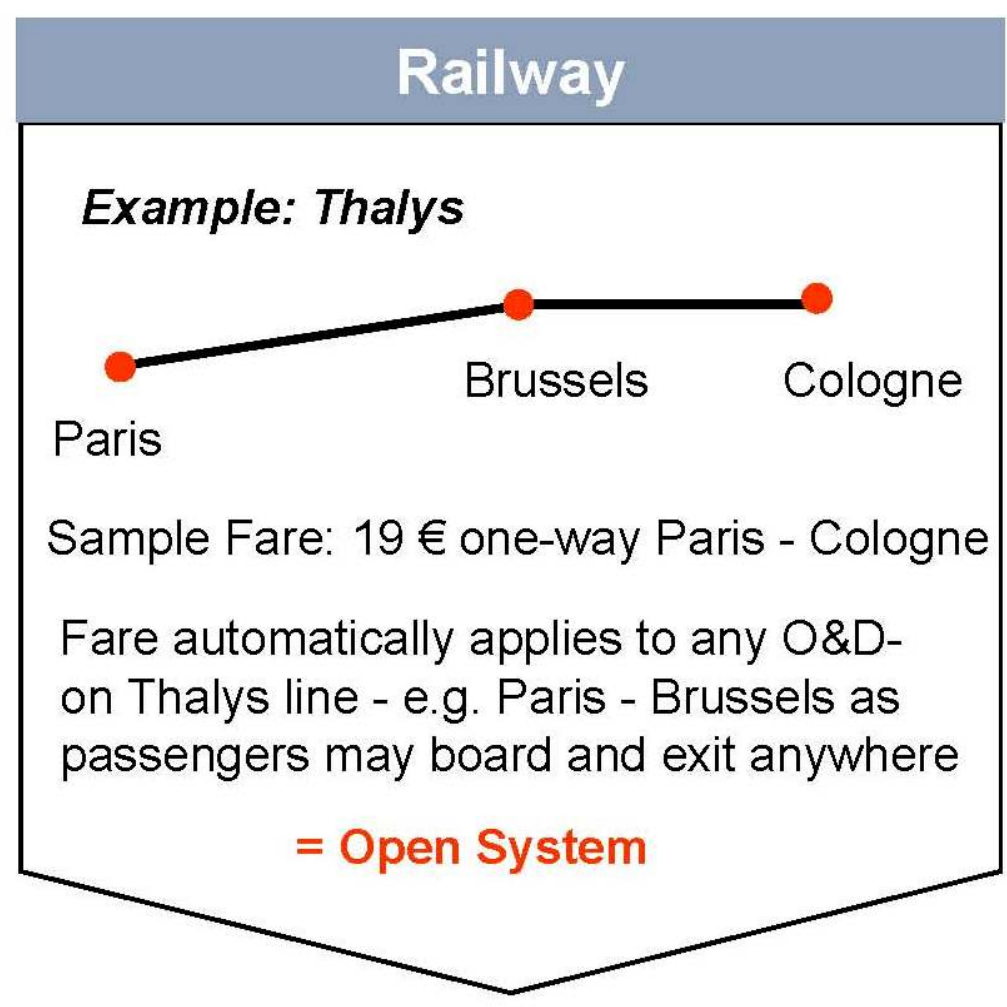

- Pricing activities may affect yields on other O\&Ds

- Unless railways screen customers according to their origin and destinations, there is a price-floor 
Figure 13: DB pricing Cologne - Berlin

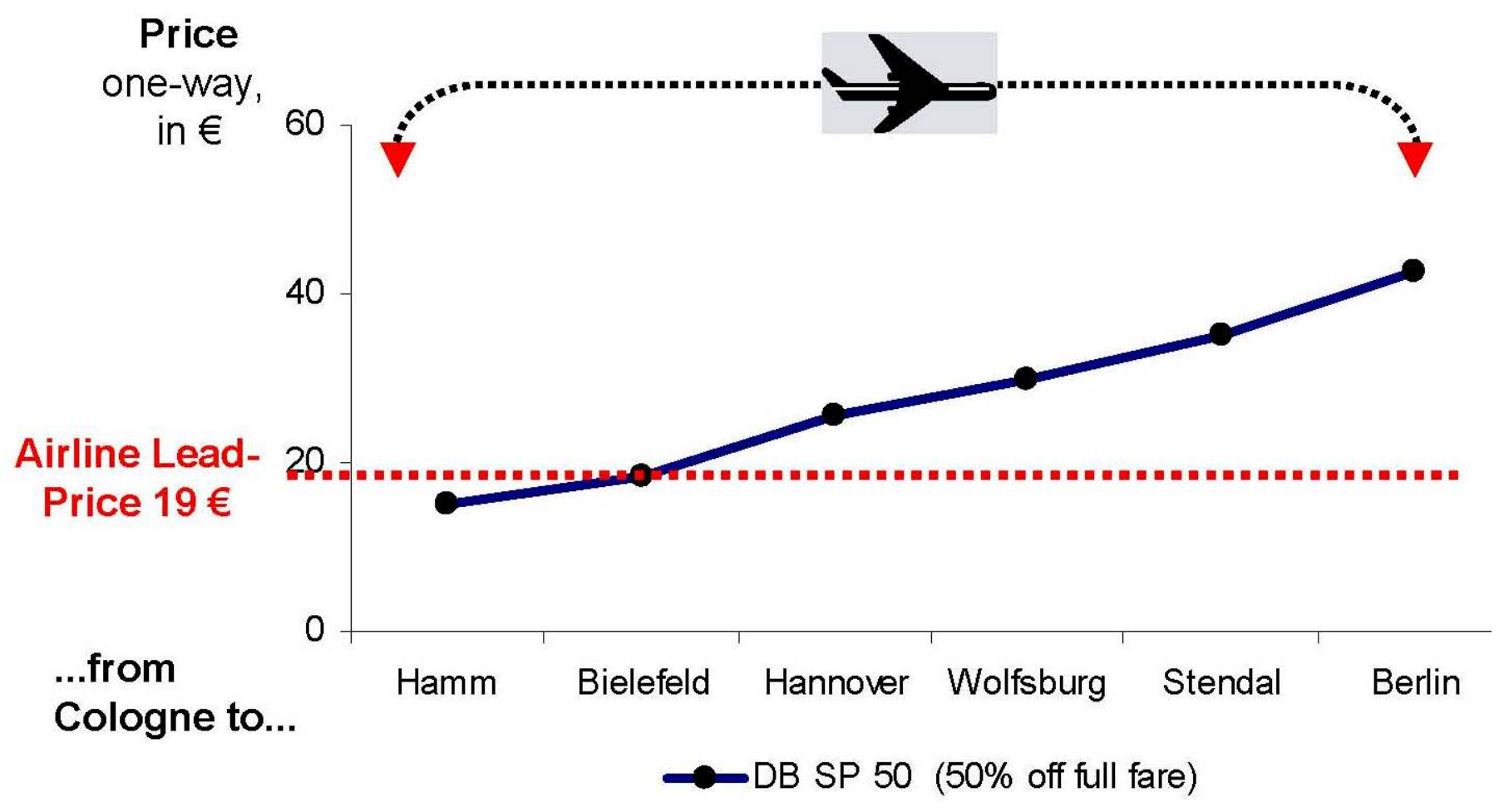

